\title{
Analysis and comparison of bio-oils obtained by hydrothermal liquefaction and fast pyrolysis of beech wood
}

\author{
Geert Haarlemmer $^{\mathrm{a}, *}$, Chamseddine Guizani ${ }^{\mathrm{a}}$, Suzanne Anouti ${ }^{\mathrm{a}}$, Maxime Déniel ${ }^{\mathrm{a}, \mathrm{b}}$, Anne Roubaud ${ }^{\mathrm{a}}$, \\ Sylvie Valin ${ }^{\mathrm{a}}$ \\ ${ }^{a}$ CEA-LITEN, Laboratoire de Thermo-Conversion des Bioressources, 17 rue des Martyrs, 38054 Grenoble, France \\ ${ }^{\mathrm{b}}$ Université de Toulouse, Ecole des Mines d'Albi, CNRS Centre RAPSODEE, 81013 Albi, France
}

\section{H I G H L I G H T S}

- Bio-oils from beech wood by hydrothermal liquefaction and fast pyrolysis.

- Physical and chemical properties of bio-oils are presented.

- Bio-oils generally have a high acidity, iodine values and residual carbon.

- Hydrothermal bio-oil has a high viscosity and low volatility.

Keywords:

Beech wood

Hydrothermal liquefaction

Fast pyrolysis

Analysis

Fuel quality

\begin{abstract}
A B S T R A C T
There are many different ways to convert biomass into liquid fuels, mostly referred to as bio-oils. This paper presents the analysis of bio-oils produced by hydrothermal liquefaction and fast pyrolysis of beech wood. Both processes have a wide panel of parameters that can be optimised influencing the oil quality. Results of the analysis show that both oils have high acidities. Iodine values indicate a high degree of unsaturations. These two qualities seem to be inversely proportional in the case of pyrolysis oils. In the case of hydrothermal conversion, additives to adjust the $\mathrm{pH}$ such as sodium hydroxide increase oil yields, lower its viscosity but do little to further improve the quality of the oils. For pyrolysis oils, increasing the severity does reduce acidity but at the expense of more unsaturations and a loss in yield. The results show that without extensive upgrading or refining, commercial fuel standards cannot be met. Specific norms and standards are being elaborated for pyrolysis used in specific installations. This paper shows how detailed analysis can help to optimise process parameters with an objective that goes beyond the mass or energy yield.
\end{abstract}

\section{Introduction}

In the search for replacement of fossil liquid fuels, a wide panel of different conversion techniques have been proposed. These include hydrothermal liquefaction, fast (or flash) pyrolysis (aided by catalysts or not) and various gasification processes followed by catalytic fuel synthesis (Fischer-Tropsch amongst others). The yield and quality of the produced liquid fuel are extremely variable from process to process.

Hydrothermal liquefaction (HTL) converts biomass in subcritical water [1]. Typical operating conditions are $260-350{ }^{\circ} \mathrm{C}$ and 8-20 MPa. At lower temperatures, hydrothermal carbonisation is

\footnotetext{
* Corresponding author. Tel.: +33 438782495; fax: +33 438785251.

E-mail address: geert.haarlemmer@cea.fr (G. Haarlemmer).
}

favoured, while higher temperatures, especially above the critical point, favour gasification. Hydrothermal liquefaction is particularly suited for wet resources as no preliminary drying is required. Wet resources that are often considered for this process include sewage sludge [2,3], food processing residues [4,5] and algae [6]. Dry resources have also been studied, including wood and forestry residues $[7,8]$ and agricultural residues [9-11]. It has been extensively shown that additives can improve bio-oil yields [2,8].

Pyrolysis is an ancient technique to produce charcoal from wood. By heating the wood in absence of an oxidising agent to $400-600^{\circ} \mathrm{C}$, it decomposes in charcoal, tar and gas. Fast pyrolysis (often referred to as flash pyrolysis) applies the same principle except that the heating rate is much higher $\left(500-1000^{\circ} \mathrm{C} \mathrm{s}^{-1}\right)$. Under these conditions the production of tar and condensable compounds are favoured at the detriment of char and gas [12]. 
The quality of the bio-oils produced depends on the process but also on the resource. Typically hydrothermal oils are very viscous, strong smelling black oils with a relatively high heating value, up to $35-40 \mathrm{MJ} / \mathrm{kg}$. Pyrolysis oils have a smoky odour, are less viscous and have a much lower heating value (similar to that of the parent biomass). Hydrothermal oils are typically proposed as a diesel substitute after catalytic upgrading [13]. Pyrolysis oils are often thought of as an alternative for fuel oil.

The objective of this paper is to present bio-oils produced by hydrothermal liquefaction and pyrolysis of beech wood, and to characterise them as much as possible. In this study, we tested various analysis techniques on six different bio-oils from HTL and entrained flow pyrolysis processes. The objective is to determine values for some of the important properties qualifying a liquid fuel. We are interested here in determining some physical and chemical properties, by testing standard methods developed to characterise biodiesel and conventional fuels.

\section{Review of analysis techniques}

There are many standards for commercial fuels, for heating and transportation applications. Each application requiring fuel is typically designed for a particular fuel for optimal performance. Inversely, most fuels target a particular application. A fuel is characterised with properties relevant to its application, including manipulation, storage and combustion. There is a very large panel of standardized tests that are applied to different fuels that are commercially available. Some of these tests are relevant to potential applications concerning bio-oils.

All commercial fuels have criteria related to storage. The iodine value (standard EN 14111) is determined to indicate if biodiesels contain compounds with unsaturated long chains like fatty acids or their derivatives resulting from the conversion of lipids. This technique has already been applied to pyrolysis oils [14]. The presence of unsaturated compounds can produce polymerisation reactions during storage. Iodine value measures the amount of unsaturation in the form of double bonds, which react with iodine compounds. The higher the iodine number, the more $\mathrm{C}=\mathrm{C}$ bonds are present in the bio-oil. The total acid number (TAN) is used as an index of fuel acidity, one of the parameters to estimate corrosion. This is an important quality measurement to avoid corrosion risk to machinery and storage tanks (standards EN 14104 and ASTM D664). Biodiesel and pyrolysis oils are often characterised with this parameter $[15,16]$.

One of the major fuel qualities is its heating value expressed by its Lower Heating Value (LHV) or Higher Heating Value (HHV) (standard NF EN 14918). Nazari et al. [17] report hydrothermal bio-oils with higher heating values in the range of $25-32 \mathrm{MJ} \mathrm{kg}^{-1}$. Vaporisation is the first stage in the combustion process. Some applications require very small amounts of residual carbon after vaporisation. This is evaluated by measuring the Conradson Carbon Residue (CCR, standards EN ISO 10370 and ASTM D4530). It is obtained after heating a fuel, and is the main indicator to identify residual carbon. Transportation fuels such as petrol, jet fuel and diesel have more narrow specifications in terms of combustion properties, for example Research Octane Number (RON, standard ASTM D2699) and cetane number (standard EN ISO 5165 and ASTM D613). These latter two are of little interest for bio-oils.

Ultimate analysis is not usually a criterion for fuels but does give interesting insights to the quality of a fuel. Typical oxygen contents for hydrothermal oils vary in the literature. Hydrothermal oils from woody biomass in batch autoclave experiments contain $20-30 \%$ oxygen according to Nazari et al. [17], 34\% according to Doassans-Carrère et al. [18] and Gan and Yuan report 28\% oxygen content for hydrothermal oil obtained from corn cobs [10]. Continuous liquefaction reactors produce biocrudes with lower oxygen content for similar biomasses, Elliot at al. report $12 \%$ $[19,20]$ while Hoffman et al. report $5 \%$ for oil produced in supercritical conditions. Pyrolysis oils contain more oxygen, around $50 \%$ on water free basis according to Doassans-Carrère et al. [18] while Zhang et al. report 35-40\% [21].

Few authors presenting hydrothermal oils complete these results in terms of functional fuel properties such as viscosity, density, volatility and stability during storage. The properties of biooils can be easily compared with commercial standards. This directs the use of bio-oils towards certain applications for example transport or heating.

Viscosities of HTL bio-oils are rarely mentioned in the literature, high values were found up to $1000 \mathrm{~Pa}$ s [7]. Furthermore, according to Mohan et al. [22] the viscosity of bio-oils increases due to the aging effect. It is well agreed that rheological properties of biooils change over time at elevated temperature by many factors like polymerisation, oxidation and others. For pyrolysis oils much more data is available. Studies on rheological properties and on the aging effects of bio-oil can be performed to give an indication on how bio-oil viscosity changes upon time depending on temperature and other storage conditions $[15,23]$. The fuel pumpability, assessed via the measure of viscosity (standards EN ISO 3104 and ASTM D445), is another important parameter.

The characterisation of chemical species in bio-oils is often performed using separation techniques such as gas chromatography coupled with mass spectrometry (GC/MS). These techniques provide an indication of the chemical nature of the bio-oil but they do not allow the quantification of all of its compounds [24,25].

Another major parameter is related to the volatility of the fuel. For storage purposes the product should be stable, vapour pressure expressed as the Reid Vapour Pressure (standard ASTM D323) should be inferior to a certain value (seasonal parameter). The boiling point range and the end of the distillation (standard ASTM D86) are also important parameters to be regulated.

Characterisation by a full distillation curve (standard ASTM D86) is rarely presented for bio-oils because they are available in small amounts at the laboratory scale. To understand the evaporation behaviour of bio-oils, other analysis techniques are applied, such as thermogravimetric analysis (TGA). TGA is applied to any type of sample that will undergo a mass change over time under the effect of temperature in a given atmosphere. The evaporation and thermal decomposition are part of the changes that will be detected by thermogravimetry. TGA is often used to predict the thermal behaviour of the major macromolecular components of biomass during their thermal conversion to biofuel [26]. In other published works, TGA is used to simulate distillation or to show the volatility of products resulting from biomass conversion. The distillation of biodiesels produced from different vegetable oils as resources are compared in term of percentage of weight loss at different temperatures [27]. Zhu et al. compared HTL bio-oils obtained from different operating conditions [28]. TGA can also be used as an alternative method to the Conradson carbon residue (CCR) method [29].

\section{Materials and methods}

\subsection{Biomass and chemicals characteristics}

The same biomass was used to produce oils by HTL and pyrolysis. The biomass is beech wood supplied by SPPS company. The raw wood is finely ground with particles having sizes ranging from tens to a few hundreds of microns. Narrow particle distributions were obtained by sieving. The wood water content was determined after drying at $105{ }^{\circ} \mathrm{C}$ according to the standard NF-EN-14774. Ash content was determined by burning the sample in air at $550{ }^{\circ} \mathrm{C}$ 
according to the standard NF-EN-14775. The ultimate analysis of the wood sample was performed by the SOCOR laboratory (France) to determine the carbon, hydrogen, nitrogen and sulphur content. These properties are summarized in Table 1.

Biomass particles having a size ranging between 315 and $450 \mu \mathrm{m}$ were used for the pyrolysis experiments. Hydrothermal experiments were performed with the same wood with particle sizes inferior to $75 \mu \mathrm{m}$.

For hydrothermal liquefaction experiments, distilled water was used to prepare the biomass slurry. Pellets of Sodium Hydroxide $\mathrm{NaOH}$ were purchased from Merck and used as received. Ethylacetate was purchased from Sigma-Aldrich and used as received. In our experiments, all the reagents were analytical grade.

\subsection{Hydrothermal liquefaction - experimental device and operating conditions}

\subsubsection{Batch reactor}

Hydrothermal liquefaction experiments are performed in a $0.6 \mathrm{~L}$ stainless steel (SS316) stirred batch reactor (Parr Instruments). In a typical experiment, the reactor is filled with approximately $240 \mathrm{~g}$ of biomass slurry prepared from beech wood and distilled water at a constant dry matter to water ratio ( $15 \mathrm{wt} \%$ dry matter). Sodium hydroxide $\mathrm{NaOH}$ is added as an additive when needed. The $\mathrm{pH}$ of the mixture is measured before and after each experiment using a Scientific Instruments IQ170 pH meter. The autoclave is leak tested, purged and pressurized to $1 \mathrm{MPa}$ with nitrogen gas, to ensure sufficient pressure for gas analysis after the reaction. The pressure inside the reactor is a function of the initial pressure, the reaction temperature and the amount of gas produced. The reactor is stirred at $600 \mathrm{rpm}$ and is heated to the reaction temperature in about $35 \mathrm{~min}$. For these experiments, the operating temperature is set at $300^{\circ} \mathrm{C}$. Once the reactor reaches the reaction temperature, it is held during a specified time within $\pm 1{ }^{\circ} \mathrm{C}$ of the specified operating temperature (holding time). For these experiments a $60 \mathrm{~min}$ holding time is applied. After the holding time, the reactor is rapidly cooled to room temperature in $20 \mathrm{~min}$ by an air quench.

\subsubsection{Product recovery}

The content of the reactor is first filtered on a Buchner filter to separate the aqueous liquid from the raw residue. The raw organic residue is sticky, and removed from the reactor as best as possible. The reactor is then weighed and the weight difference with the empty reactor is counted as raw organic residue (wet). The raw organic residue is dried at room temperature under air circulation until a stable mass is obtained.

The raw organic residue is then extracted with ethyl-acetate; using a tenfold amount of solvent $(w / w)$ to separate the bio-oil from the char. Bio-oil is recovered after evaporation of the solvent at room temperature under air circulation until a stable weight is obtained. It is assumed that no residual solvent is left in the

\section{Table 1}

Proximate and ultimate analysis of the beech wood.

\begin{tabular}{ll} 
Proximate analysis & \\
Moisture (wt\%) & 8.7 \\
Volatile matter (wt\% dry basis) & 84.3 \\
Fixed carbon (wt\% dry basis) & 15.2 \\
Ash $\left(550^{\circ} \mathrm{C}\right)$ (wt\% dry basis) & 0.80 \\
Ash $\left(815^{\circ} \mathrm{C}\right)$ (wt\% dry basis) & 0.46 \\
Ultimate analysis (wt\% dry basis) & \\
$\mathrm{C}$ & 49.1 \\
$\mathrm{H}$ & 5.7 \\
$\mathrm{~N}$ & $<0.3$ \\
$\mathrm{~S}$ & 0.05 \\
$\mathrm{O}$ (by difference) & 44.5 \\
\hline
\end{tabular}

bio-oil. The char is also dried at room temperature under air circulation until a stable weight is obtained. Weight loss of the raw residue after extraction and drying is used to determine the proportion of solvent-soluble organics in the raw residue, and therefore the bio-oil and char yields.

\subsection{Fast pyrolysis - experimental device and operating conditions}

The experimental device is a Drop Tube Reactor (DTR) located at the School of Mines in Albi, France. The device was previously used in several studies focusing on the pyrolysis and gasification of biomass [30-32].

The experimental device consists of three main parts, the biomass injection system, the reactor and the collection of the reaction products. The reactor is an alumina tube inserted in a vertical heater with three independent heating zones. The dimensions of the tube are $2.3 \mathrm{~m}$ in length and $0.075 \mathrm{~m}$ in internal diameter. The heated zone is $1.2 \mathrm{~m}$ long. The reactor works at atmospheric pressure and can reach a maximum temperature of $1400^{\circ} \mathrm{C}$. The wood particles are continuously fed into the reactor using a gravimetric feeding system. The main gas stream (nitrogen) is preheated to the pyrolysis temperature before entering the reactor.

The solid char falls by gravity into a collection pot. Tars and light gases goes into a cold trap at $-77^{\circ} \mathrm{C}$ (isopropanol + solid $\mathrm{CO}_{2}$ ), then in a filter lined with glass wool fibres. Tars are trapped after these two condensation stages while light gases are aspired towards a gas chromatograph for analysis.

This staged condensation allowed us to obtain two bio-oil fractions. The first one, obtained in the cold trap, has a high water content (aqueous fraction), while the second one which is obtained after the condensation in the glass wool fibres lined pot, contains much less water and mostly organic molecules (organic fraction). The focus of the present work is on the bio-oil organic fraction. The mass balance is obtained after weighing the char in the pot, the tar collection pot before and after the experiment and by calculating the amount of gases after analysis.

\subsection{HTL and pyrolysis product analysis}

Most of the techniques used in this paper are based on standard, well known, techniques. High viscosity and the deep black colour of hydrothermal oils impose some adaptations from the standard methods are required due to for example colour indicators.

\subsubsection{Total acid number (TAN) and iodine value}

These criteria are concerned with stability and corrosion during storage. The total acid number (TAN) and the iodine value are determined according to the generic (applicable to most fuels) European standards EN 14104 (2003) and EN 14111 (2003) respectively. The titration experiments were repeated three times for each method.

The total acid number is the number of milligrams of potassium hydroxide $(\mathrm{KOH})$ that is required to neutralise the acidic functions present in one gram of bio-oil. It is expressed in $\mathrm{mg} \mathrm{KOH}$ per gram of sample. To determine the TAN value, $50 \mathrm{mg}$ of bio-oil sample was dissolved in $10 \mathrm{ml}$ of isopropyl alcohol and then titrated by a $\mathrm{KOH}$ solution $\left(0.02 \mathrm{~mol}^{-1}\right)$ using Phenolphthalein as a colour indicator. The standard EN 14104 suggests using $0.1 \mathrm{~mol} \mathrm{l}^{-1}$ but working with a lower concentration allows using smaller samples to assure the transparency of the solution. Temperature at equivalent point was controlled according to the standard method.

Iodine value is the mass of halogen binding to double-bonds contained in $100 \mathrm{~g}$ of bio-oil. It is expressed in grams of iodine $\left(\mathrm{I}_{2}\right)$ per $100 \mathrm{~g}$ of the sample, according to the standard EN 14111. It is based on the reaction between a Wijs (ICl) solution and the 
double-bonds contained in constituents of the bio-oil. Excess of the Wijs reagent becomes $\mathrm{I}_{2}$ by adding potassium iodide (KI). The concentration of formed iodine $\mathrm{I}_{2}$ is then determined by titration with sodium thiosulfate. Bio-oil samples of $90-100 \mathrm{mg}$ were used for iodine value measurements.

\subsubsection{GC/MS analysis}

GC/MS (gas chromatography/mass spectroscopy) analysis of bio-oil was performed in Clarus 500/600S Perkin Elmer apparatus. The column used is a DB-1701 capillary column $60 \mathrm{~m} \times 0.25 \mathrm{~mm}$, $0.25 \mu \mathrm{m}$ film thickness. The injection of $1 \mu \mathrm{l}$ of bio-oil samples is performed on Split mode 10:1 with Helium as carrier gas. The injector temperature is maintained at $250^{\circ} \mathrm{C}$. The GC oven temperature is programmed from $45^{\circ} \mathrm{C}(10 \mathrm{~min})$ to $230^{\circ} \mathrm{C}$ at a rate of $6{ }^{\circ} \mathrm{C} \mathrm{min}^{-1}$, and held at $230{ }^{\circ} \mathrm{C}$ during $9.17 \mathrm{~min}$. It is then raised to $250{ }^{\circ} \mathrm{C}$ at a rate of $10^{\circ} \mathrm{C} \mathrm{min}-1$, held at $250{ }^{\circ} \mathrm{C}$ during $20 \mathrm{~min}$. The transfer interface and the ion source in the mass spectrometer are maintained at $230^{\circ} \mathrm{C}$. Bio-oil samples dissolved in ethyl acetate are filtered with a $0.45 \mu \mathrm{m}$ PTFE filter before analysis. The National Institute of Standards and Technology (NIST) mass spectral library is used to identify the compounds.

\subsubsection{Thermogravimetric analysis}

The thermogravimetric (TG) analysis (referred to as TGA) was conducted on a SETSYS SETARAM device using a platinum pan at atmospheric pressure. The oil is heated at $10^{\circ} \mathrm{C} \mathrm{min}^{-1}$ from $60^{\circ} \mathrm{C}$ to $900{ }^{\circ} \mathrm{C}$ under nitrogen flow $\left(50 \mathrm{ml} \mathrm{min}^{-1}\right)$. The final temperature is maintained for $10 \mathrm{~min}$ and air is introduced $\left(50 \mathrm{ml} \mathrm{min}^{-1}\right)$ to perform the combustion stage. Sample mass of the analysed biooil are typically 5-6 mg. The TG curve shows weight loss as function of the temperature. This gives precious information on the volatility of the bio-oil and allows the evaluation of the carbon residue.

\subsubsection{Higher heating value}

The higher heating value HHV of bio-oils (typically samples of 0.3-0.5 g) is measured using a Parr 6200 bomb calorimeter (Parr Instruments Company).

\subsubsection{Viscosity measurements}

Dynamic viscosity of the bio-oils is measured using a rotational viscometer with a temperature controlled sample chamber. The viscometer was supplied by the Sheen society; it is composed of a sample cell placed in a thermostat adapter, and a range of different geometric spindles. A sample volume between 8 and $11 \mathrm{ml}$ is required for each measurement depending on the spindle. The torque required to rotate the spindle at the required frequency is measured. The viscosity is calculated from torque measurement and the geometry of the spindle. In practice the measurement is reliable between $15 \%$ and $85 \%$ of the maximum torque, resulting in a limited operating window for each configuration.

\subsubsection{Density}

Density is measured by two different methods. For pyrolysis oils with a sufficiently low viscosity a known volume is filled with the oil and weighed. Hydrothermal oils are too viscous for the previous method to be accurate, due to presence of air bubbles perturbing the measurement. A special density module was used on a high precision balance that allows the density measurement of an object with an arbitrary shape. The method consists of weighing the sample directly followed by a weighing under water. The difference in weight is created by buoyancy and represents the sample volume.

\section{Results}

\subsection{Conversion results}

\subsubsection{Hydrothermal liquefaction}

Bio-oils have been produced by hydrothermal liquefaction at $300{ }^{\circ} \mathrm{C}, 60 \mathrm{~min}$ holding time. Two different operating conditions are presented here. In the first case (L1), HTL of beech wood was performed in water without any additive. In the second case (L2), $0.06 \mathrm{~g}$ of sodium hydroxide per gram of beech wood was added. In both cases the amount of raw residue (after drying) as well as the char and oil yields are presented (Table 2). As seen earlier in Section 3.2.2, the oil yield is the solvent soluble fraction. All yields are given relative to the initial mass of dry biomass used in the conversion. Each experiment was performed three times. The averaged value of the results is reported, the reported uncertainty is the span in the data rather than a standard deviation.

The presence of sodium hydroxide clearly does not have any influence on the final $\mathrm{pH}$ and on the gas production. The presence of a strong base favours the production of oil and appears to inhibit the formation of char. The produced gas mainly consists of carbon dioxide with traces of ethane, ethylene and propane. The total amount of organic molecules in the aqueous phase cannot be assessed directly. Due to oxygen transfers (hydration and dehydration reactions) between water and the biomass and the production of $\mathrm{CO}_{2}$, the mass balance can only be closed when the water present in the reactor is taken into account. The reported yield of the aqueous phase is calculated by difference as is common practice in this type of study. In practice, about $35 \%$ of the initial organic material is dissolved in the water phase.

\subsubsection{Fast pyrolysis}

Four pyrolysis oils were produced at different temperatures ranging between $450{ }^{\circ} \mathrm{C}$ and $600{ }^{\circ} \mathrm{C}$. The particle size and gas residence time were maintained constant at $315-450 \mu \mathrm{m}$ and $16.6 \mathrm{~s}$ respectively. The biomass feeding rate was set at $1 \mathrm{~g} \mathrm{~min}^{-1}$. The pyrolysis tests durations were between 60 and $90 \mathrm{~min}$ at temperatures from 450 to $600{ }^{\circ} \mathrm{C}$.

The results of fast pyrolysis tests are given in Table 3 . The yield of the organic fraction (analysed in the present study) is always lower than that of the aqueous fraction. However, this organic fraction is of higher interest as it contains less water and a higher concentration of organics. The mass balances are relatively well closed. No duplicate runs were made. An assessment of all experimental uncertainties evaluated the experimental uncertainty at $10 \%$.

When considering the effect of the temperature on the pyrolysis products distribution, one can see that the lowest temperature of $450{ }^{\circ} \mathrm{C}$ corresponds to the highest solid yield (40.6\%) and the lowest gas yield (6.1\%). At the highest temperature of $600{ }^{\circ} \mathrm{C}$ the gas production is maximised (51.5\%), while the solid char yield is the lowest (8.2\%). The production of bio-oil reaches a maximum at $500{ }^{\circ} \mathrm{C}(62.4 \%)$ and decreases at higher temperatures. These observations can be explained by the fact that the reaction kinetics of the wood pyrolysis reaction is relatively low at $450{ }^{\circ} \mathrm{C}$ and increases with the temperature. The characteristic pyrolysis time

Table 2

Results of hydrothermal liquefaction experiments.

\begin{tabular}{lll}
\hline & L1 without additives & L2 with $\mathrm{NaOH}$ \\
\hline Initial/final pH & $5.4 / 5.5$ & $10.2 / 5.6$ \\
Raw residue yield (dry) & $44( \pm 1) \%$ & $48( \pm 2) \%$ \\
Char yield & $30( \pm 2) \%$ & $19( \pm 1) \%$ \\
Bio-oil yield & $14( \pm 2) \%$ & $28( \pm 2) \%$ \\
Gas yield & $20( \pm 2) \%$ & $17( \pm 1) \%$ \\
Aqueous phase by difference & $36( \pm 3) \%$ & $35( \pm 2) \%$ \\
\hline
\end{tabular}


Table 3

Product yields and mass balances for the different pyrolysis tests (uncertainty results estimated at $10 \%)$

\begin{tabular}{lrllrlr}
\hline \multicolumn{3}{c}{ Yields (\%) } & \multicolumn{2}{l}{$\begin{array}{l}\text { Closure } \\
\text { (\%) }\end{array}$} \\
\cline { 2 - 6 } & Char & $\begin{array}{l}\text { Aqueous } \\
\text { fraction of } \\
\text { the oil }\end{array}$ & $\begin{array}{l}\text { Organic } \\
\text { fraction of } \\
\text { the oil }\end{array}$ & Gas & $\begin{array}{l}\text { Non-condensed } \\
\text { water }\end{array}$ & \\
\hline $450{ }^{\circ} \mathrm{C}$ & 40.6 & 29.6 & 17.9 & 6.1 & 6.3 & 100.5 \\
$500{ }^{\circ} \mathrm{C}$ & 13.6 & 45.2 & 17.2 & 15.0 & 6.0 & 97.1 \\
$550^{\circ} \mathrm{C}$ & 10.3 & 33.6 & 14.8 & 25.6 & 8.6 & 92.9 \\
$600{ }^{\circ} \mathrm{C}$ & 8.2 & 30.1 & 9.5 & 51.5 & 4.9 & 104.3 \\
\hline
\end{tabular}

is about $2 \mathrm{~s}$ at $450{ }^{\circ} \mathrm{C}$ and decreases to $0.15 \mathrm{~s}$ at $600{ }^{\circ} \mathrm{C}$ leaning on the results of [33]. The cracking kinetics of the condensable species increases with temperature leading to a higher gas and lower biooil yields with increasing temperature.

\subsection{Physical properties of bio-oils}

Physical properties are important parameters as they relate to transport and storage. In this study we present density and viscosity measurements. Key values are given in Table 4 . For $450^{\circ} \mathrm{C}$ the results are presented for the totally condensed phase with water included, and denoted with the -Liq extension. The -Org extension indicates the condensed organic phase. Each experiment was performed three times except for the viscosity that was measured only on one sample. The averaged value of the results is reported, the reported uncertainty is the span in the data rather than a standard deviation.

Fig. 1 presents the evolution of the viscosity of hydrothermal oils L1 and L2 with the temperature and the frequency of the viscometer. The rotating viscometer can operate with a range of frequencies. The actual frequencies depend on the minimum and maximum torque measurement on the motor. The viscosity of hydrothermal oil L1 was found to be very high at room temperature: at $30^{\circ} \mathrm{C}$ the value was $700 \mathrm{~Pa}$ s and only the lowest frequency was possible to avoid excessive torque on the motor. At higher temperatures the viscosity decreases rapidly to $520 \mathrm{mPa} \mathrm{s}$ at $80^{\circ} \mathrm{C}$. For higher temperatures the full range of allowed frequencies was used. Hydrothermal oil L2 has a much lower viscosity but its evolution with the temperature is less pronounced. It was observed that the measured viscosity decreases with the frequency and therefore the shear rate. Towards higher frequencies the viscosity approaches an asymptotic value. The fluid is not perfectly Newtonian, something that is to be expected from this type of complex fluids. This means that the measured value of the viscosity measured is not a precise data but depends on the measuring device. It should be taken as an order of magnitude value. The fluid becomes more Newtonian with higher temperatures and the values are more precise.

The viscosities of pyrolysis oils (see Fig. 2) are much lower than those obtained after hydrothermal liquefaction. The viscosity decreases with increasing temperatures. As noted earlier, bio-oil P1 is the totally condensed phase from the fast pyrolysis

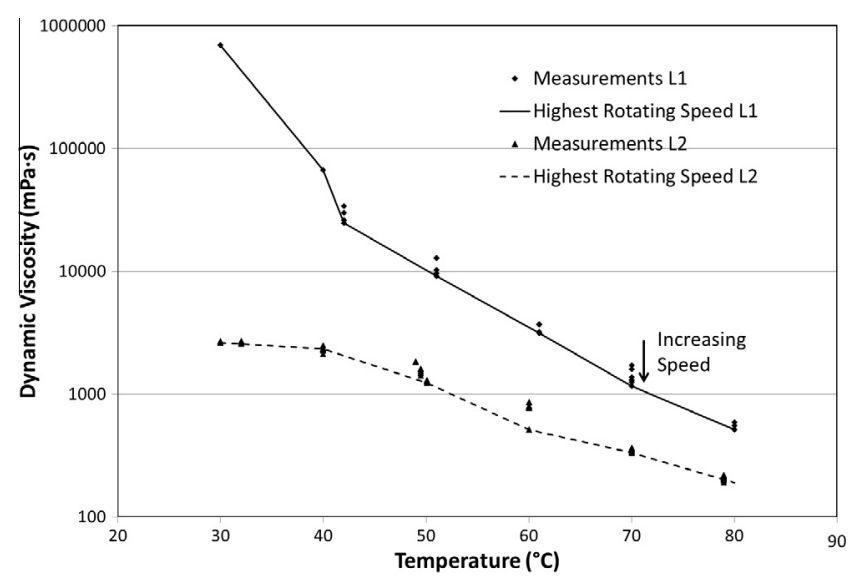

Fig. 1. Evolution of the viscosity of hydrothermal bio-oil L1 with temperature.

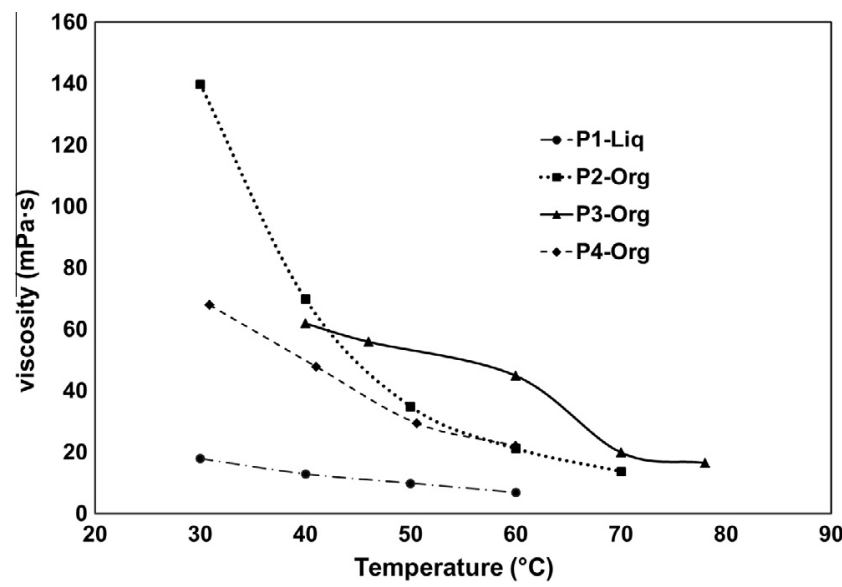

Fig. 2. Evolution of the viscosity of pyrolysis oils with temperature.

experiments. Its viscosity is much lower than that of the other samples, due to the presence of a non-negligible amount of water. The presence of water is not desirable for energy recovery application; yet it decreases the oil viscosity and therefore enhances its pumpability. Bio-oils P2 to P4 are exclusively the organic fraction of the oil; the water phase is condensed independently. There appears to be no clear correlation between operating conditions and the viscosities of oil P2, P3 and P4. Of the three organic fractions P4 appears to have the lowest viscosity. An obvious explanation can be found in the fact that higher pyrolysis temperature produces lower molecular weight molecules. At $70-80^{\circ} \mathrm{C}$ the viscosities converge to $20 \mathrm{mPa}$.

The evaporation behaviour is evaluated by thermogravimetric analysis. Thermogravimetric analyses of bio-oils produced by hydrothermal conversion are presented in Fig. 3. To compare biooils with classic refinery streams, the thermogravimetric analyses

Table 4

Physical properties of bio-oils (uncertainty is globally estimated at $10 \%$, except when detailed).

\begin{tabular}{|c|c|c|c|}
\hline Oil & Density $\left(22^{\circ} \mathrm{C}\right)\left(\mathrm{kg} \mathrm{m}^{-3}\right)$ & Viscosity @ $40^{\circ} \mathrm{C}$ (mPa s) & Viscosity @ $80^{\circ} \mathrm{C}$ (mPa s) \\
\hline L1 & $1.14( \pm 0.02)$ & $67,000( \pm 5000)$ & $520( \pm 40)$ \\
\hline L2 & $1.14( \pm 0.02)$ & $2200( \pm 200)$ & $210( \pm 10)$ \\
\hline $450^{\circ} \mathrm{C}-\mathrm{Liq}$ & 1.1 & 13 & 7 \\
\hline $500^{\circ} \mathrm{C}-$ Org & 1.1 & 70 & 19 \\
\hline $550^{\circ} \mathrm{C}-\mathrm{Org}$ & 1.1 & 43 & 20 \\
\hline $600^{\circ} \mathrm{C}-$ Org & 1.1 & 56 & 40 \\
\hline
\end{tabular}




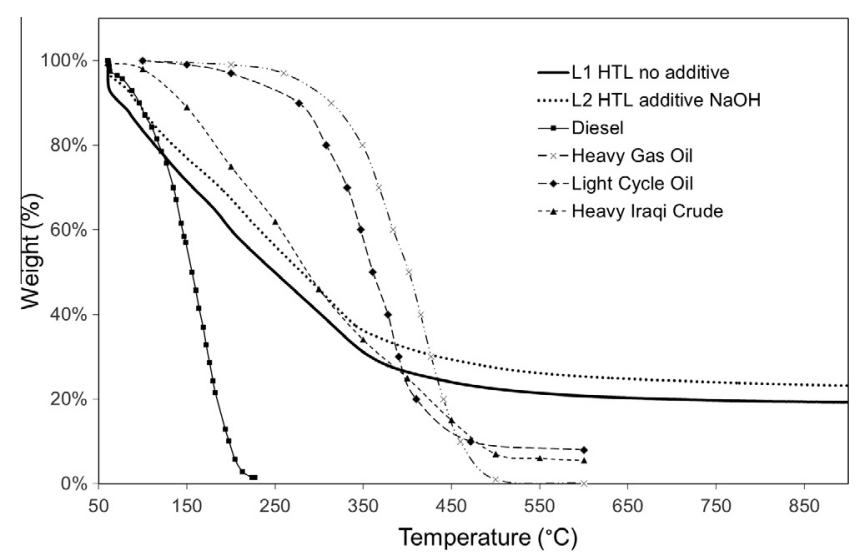

Fig. 3. Thermogravimetric analysis of hydrothermal bio-oils.

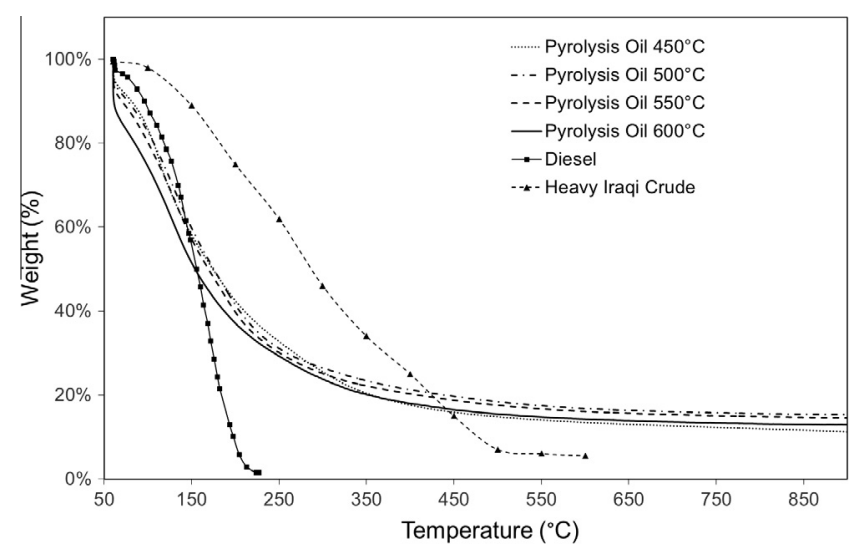

Fig. 4. Thermogravimetric analysis of pyrolysis bio-oils.

of Iraqi heavy crude [34], diesel oil [35] as well as a light cycle oil and a heavy gas oil from Brazilian crudes [36] are presented in the same graph. Pyrolysis bio-oils are presented in Fig. 4. Pyrolysis oils initially follow the diesel curve but after evaporating 50\% of their mass the evaporation slows down significantly. This indicates that pyrolysis oils contain more high boiling point (high molecular weight) compounds. In all cases, especially for hydrothermal oils, the residual carbon after evaporation is much higher than for most refinery streams ranging between $11 \%$ to $13 \%$ for pyrolysis oils and $17 \%$ to $24 \%$ for hydrothermal oils.

The evaporation behaviour of the bio-oils is presented in a more quantitative way in Table 5. For pyrolysis oils, the volatility between 35 and $100{ }^{\circ} \mathrm{C}$ or 35 and $250{ }^{\circ} \mathrm{C}$ increases with increasing pyrolysis severity. Hydrothermal and pyrolysis oils have a comparable volatility below $100^{\circ} \mathrm{C}$, but hydrothermal oils appear to contain more high boiling compounds. Nazari et al. [17] performed a similar experiment for hydrothermal oil produced under similar

Table 5

Fractions evaporated at different temperature ranges (uncertainty estimated at $1 \%$ ).

\begin{tabular}{llll}
\hline Oil & $35-100{ }^{\circ} \mathrm{C}$ & $35-250{ }^{\circ} \mathrm{C}$ & $250-900{ }^{\circ} \mathrm{C}$ \\
\hline L1 & 17 & 50 & 31 \\
L2 & 12 & 44 & 33 \\
P1-Org & 17 & 67 & 22 \\
P2-Org & 17 & 69 & 18 \\
P3-Org & 20 & 70 & 17 \\
P4-Org & 26 & 71 & 16 \\
\hline
\end{tabular}

conditions with birch wood. Oil was obtained from solvent extraction and solvent evaporation under reduced pressure. They found much higher evaporation temperatures; little activity was shown under $180^{\circ} \mathrm{C}$ with a peak in the evaporation around $380^{\circ} \mathrm{C}$. At $400{ }^{\circ} \mathrm{C} 46 \%$ was evaporated while in our oils this degree of evaporation is achieved at $250{ }^{\circ} \mathrm{C}$. It is difficult to comment on the reason for this difference, probably due to more severe solvent evaporation conditions.

\subsection{Chemical properties of bio-oils}

All oils have been analysed for a wide spectrum of properties such as total acid number (TAN), iodine value, heating value and residual carbon after evaporation. The results are presented in Table 6. The first major observation is that the heating value of hydrothermal oils is higher than that of pyrolysis oils and that they contain less water. Hydrothermal oils have a higher molecular weight than pyrolysis oils; this is confirmed by their higher viscosity and their tendency to produce residual carbon during heating and evaporation. Acidity of the oils depends much on the conversion process. The addition of a strong base in the HTL process significantly reduces the acidity of the oil (L2 compared to L1). The ash content of the bio-oils is negligible as the parent biomass contains very little ashes. Sodium added for the production of hydrothermal oil L2 is mainly found in the water phase.

Higher temperatures reduce the acidity of the pyrolysis oils. This may be due to dehydration and decarboxylation reactions of carboxylic acids, which are thermally favoured above $450{ }^{\circ} \mathrm{C}$ $[37,38]$. Acetic acid can dehydrate to form water and acetic anhydride (reaction (1)). Moreover, thermal decomposition of acetic acid can yield formaldehyde along with carbon monoxide and ethylene (reaction (2)). Finally, acetic acid is able to undergo decarboxylation to form methane and carbon dioxide (reaction (3)). We observed in our experiments an increase of the formaldehyde yield, as well as of $\mathrm{CO}, \mathrm{CO}_{2}, \mathrm{CH}_{4}$ and $\mathrm{C}_{2} \mathrm{H}_{4}$ (results not shown).

$$
\begin{aligned}
& 2 \mathrm{CH}_{3} \mathrm{CO}_{2} \mathrm{H} \rightarrow \mathrm{H}_{2} \mathrm{O}+\left(\mathrm{CH}_{3} \mathrm{CO}\right)_{2} \mathrm{O} \\
& 2 \mathrm{CH}_{3} \mathrm{CO}_{2} \mathrm{H} \rightarrow 2 \mathrm{CH}_{2} \mathrm{O}+2 \mathrm{CO}+\mathrm{C}_{2} \mathrm{H}_{4} \\
& \mathrm{CH}_{3} \mathrm{CO}_{2} \mathrm{H} \rightarrow \mathrm{CO}_{2}+\mathrm{CH}_{4}
\end{aligned}
$$

This same phenomenon can be observed when comparing the results presented in this paper with the results from Hoffman et al. [39]. These authors show that for hydrothermal oils produced from hardwood at $400^{\circ} \mathrm{C}$ have a lower acidity, $37 \mathrm{mg} \mathrm{KOH}$ per gram bio-oil. Higher temperatures increase the iodine value of pyrolysis oils, corresponding to an increase of monomeric lignin derivatives with unsaturated side-chains (see also Fig. 6).

Fig. 5 shows the GC/MS analysis of the hydrothermal oils. The peaks in Fig. 5 are partially identified in Table 7. In practice there are many peaks, sometimes overlaying, which makes positive identification difficult. Only compounds with a positive identification are presented. The peaks of phenolic compounds (phenol, guaiacol and syringol) are less important, relative to the other compounds, in the oil produced in presence of sodium hydroxide. This is probably due to a solubilisation of these compounds in the water phase in the presence of a strong base. However, the presence of sodium hydroxide in the conversion process only moderately influences the chemical composition.

The thermogravimetric analysis shows that about $50 \%$ of the hydrothermal oil is evaporated at $250{ }^{\circ} \mathrm{C}$, the maximum furnace temperature of the GC/MS. This means that only half of the oil is actually evaporated in the GC/MS and therefore analysed. Many high molecular weight compounds cannot be analysed. In the case of pyrolysis oil only $30 \%$ of the oil cannot be analysed.

The GC/MS analyses of pyrolysis oils are presented in Fig. 6 . The peaks in Fig. 6 are partially identified in Table 7. We observe that 
Table 6

Chemical properties of bio-oils.

\begin{tabular}{|c|c|c|c|c|c|c|c|c|}
\hline Oil & $\mathrm{HHV}\left(\mathrm{MJ} \mathrm{kg}^{-1}\right)$ & Residual carbon (\%) & TAN (mg KOH per gram oil) & Iodine value & Water content (\%) & C $(\%)$ & $\mathrm{H}(\%)$ & $\mathrm{O}(\%)^{\mathrm{a}}$ \\
\hline L1 & $27.0( \pm 0.5)$ & $17( \pm 1)$ & $67( \pm 4)$ & $127( \pm 3)$ & $<1$ & $68.2( \pm 0.6)$ & $6.8( \pm 0.1)$ & 27.3 \\
\hline $\mathrm{L} 2$ & $30.1( \pm 0.5)$ & $24( \pm 1)$ & $32( \pm 3)$ & $126( \pm 3)$ & $<1$ & $64.8( \pm 0.3)$ & $7.0( \pm 0.1)$ & 24.0 \\
\hline P1-Org & $21.7( \pm 0.5)$ & $11( \pm 1)$ & $109( \pm 17)$ & $163( \pm 7)$ & $21( \pm 1)$ & NA & NA & NA \\
\hline P2-Org & $21.4( \pm 0.5)$ & $13( \pm 1)$ & $89( \pm 14)$ & $147( \pm 1)$ & $11( \pm 1)$ & 40.8 & 6.5 & 52.8 \\
\hline P3-Org & $23.3( \pm 0.5)$ & $13( \pm 1)$ & $45( \pm 6)$ & $203( \pm 13)$ & $10( \pm 1)$ & 35.6 & 6.8 & 57.6 \\
\hline P4-Org & $25.1( \pm 0.5)$ & $13( \pm 1)$ & $46( \pm 5)$ & $164( \pm 1)$ & $7.8( \pm 0.1)$ & NA & NA & NA \\
\hline
\end{tabular}

a Calculated by difference.

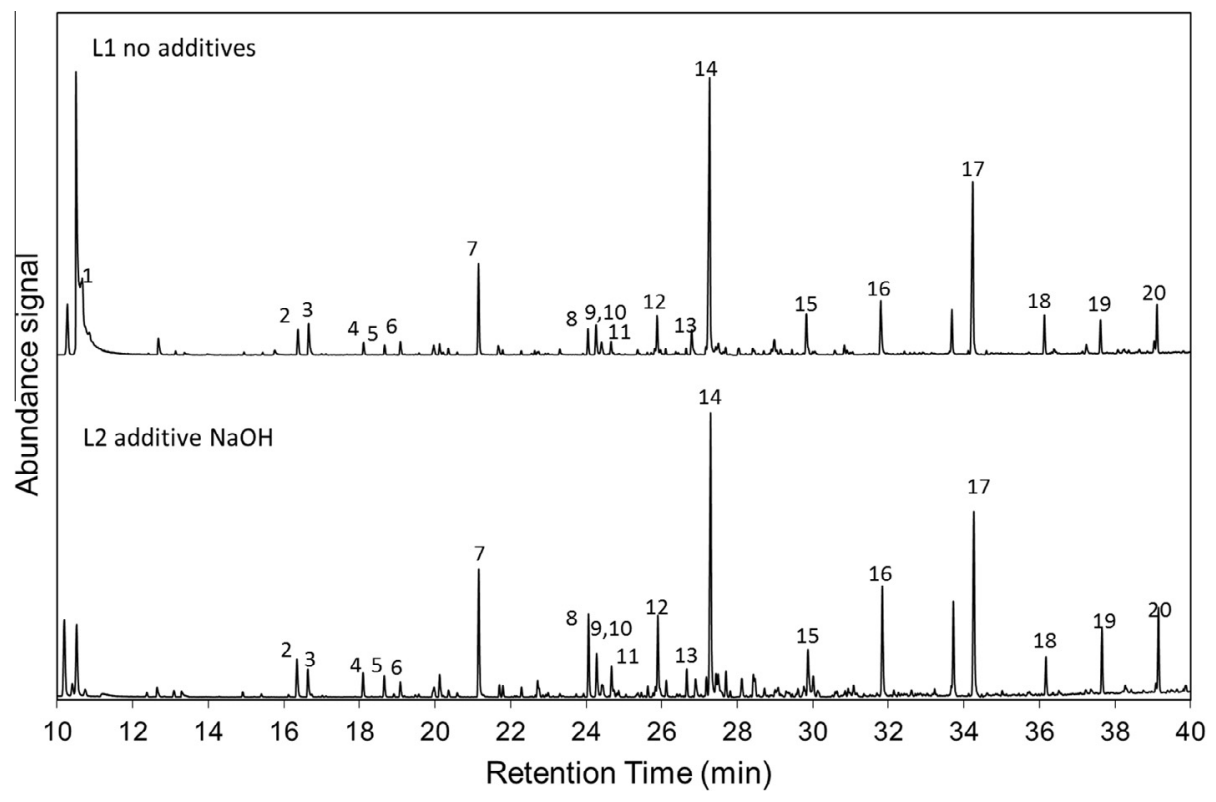

Fig. 5. GC/MS analysis of hydrothermal oils.

Table 7

Identification of GC/MS peaks in hydrothermal oils (left) and pyrolysis oils (right).

\begin{tabular}{|c|c|c|c|}
\hline & Hydrothermal oils (Fig. 5) & & $\begin{array}{l}\text { Pyrolysis oils } \\
\text { (Fig. 6) }\end{array}$ \\
\hline 1 & Acetic acid & 1 & Formaldehyde \\
\hline 2 & Cyclopentanone & 2 & Acetique acid \\
\hline 3 & Methyl-pyrazine & 3 & Hydroxyacetone \\
\hline 4 & 2-Methyl-2-cyclopentanone & 4 & Toluene \\
\hline 5 & (R)-(+)-3-methylcyclopentanone & 5 & Cyclopentanone \\
\hline 6 & Cyclopenten-1-one & 6 & o-xylene \\
\hline 7 & 2-Methyl-2-cyclopenten-1-one & 7 & Furfural \\
\hline 8 & 2,3-Dimethyl-2-cyclopenten-1-one & 8 & $\begin{array}{l}\text { 2-Methyl-1-ethyl- } \\
\text { benzene }\end{array}$ \\
\hline 9 & 3-Methyl-2-cyclopenten-1-one & 9 & Butyrolactone \\
\hline 10 & 3-Methyl-butyrolactone + unknown & 10 & 2-Furanone \\
\hline 11 & 3,5-Dimethyl-2-cyclopenten-1-one & 11 & Phenol \\
\hline 12 & 3,4-Dimethyl-2-cyclopenten-1-one & 12 & Guaïacol \\
\hline 13 & Phenol & 13 & Phenol-2-methyl \\
\hline 14 & Guaiacol & 14 & 2,5-Dimethylphenol \\
\hline 15 & $\begin{array}{l}\text { Methoxy-5-methylphenol (methyl- } \\
\text { guaiacol) }\end{array}$ & 15 & Syringol \\
\hline 16 & 2-Hydroxypyridine-4-carboxyaldehyde & 16 & Methoxyeugenol \\
\hline 17 & $\begin{array}{l}\text { 2,6-Dimethoxy-phenol (syringol) } \\
+ \text { unknown }\end{array}$ & & \\
\hline 18 & 2-Methyl-1,4-benzenediol & & \\
\hline 19 & 5-Tert-butylpyrogallol & & \\
\hline 20 & $\begin{array}{l}\text { 1-(4-Hydroxy-3-methoxyphenyl)-2- } \\
\text { Propanone (vanilloylmethyl cetone or } \\
\text { guaiacylacetone) }\end{array}$ & & \\
\hline
\end{tabular}

many compounds are identified both in hydrothermal and pyrolysis oils. With increasing severity in the pyrolysis, some of the peaks of the larger molecules (cyclopentanone) are reduced and smaller molecules are favoured (formaldehyde and acetic acid). Thermogravimetric analysis showed that $30 \%$ of the pyrolysis oil is not evaporated at the maximum temperature of the GC/MS furnace. Many new molecules are present in the chromatogram at retention times between 30 and $37 \mathrm{~min}$. It is possible (even likely) that these compounds are the results of cracking reactions of high-boiling point compounds, which were not visible previously.

Some molecules like acetic acid, hydroxyacetone and formaldehyde are present in the four oils and have relatively constant peak areas, independent on the temperature. Some other molecules show significant changes as to their peak area. For instance, toluene only appears at $550{ }^{\circ} \mathrm{C}$ and shows an increase in its peak area at $600^{\circ} \mathrm{C}$. This molecule probably results from the cracking reaction of heavier molecules. A similar observation can be made for the o-xylene which also appears at $550^{\circ} \mathrm{C}$ but has its peak area decreasing at $600^{\circ} \mathrm{C}$. This is probably due to thermal cracking. This molecule may give a molecule of toluene or benzene by losing one or two methyl groups respectively.

It can also be noted that monocyclic molecules such as phenol, guaiacol and dimethylphenol have their areas increasing with temperature. These are also likely outcome of the cracking reactions of larger molecules.

Other monocyclic molecules such as dimethoxyphenol (syringol) and methoxyeugenol show lower peak areas with increasing temperature. A plausible explanation could be that such molecules would lose their side chains by thermal cracking to give simpler molecules such as phenol or toluene and more gas in the form of $\mathrm{CO}, \mathrm{H}_{2}, \mathrm{CH}_{4}$ and $\mathrm{CO}_{2}$, which would be consistent with our experimental observations. 


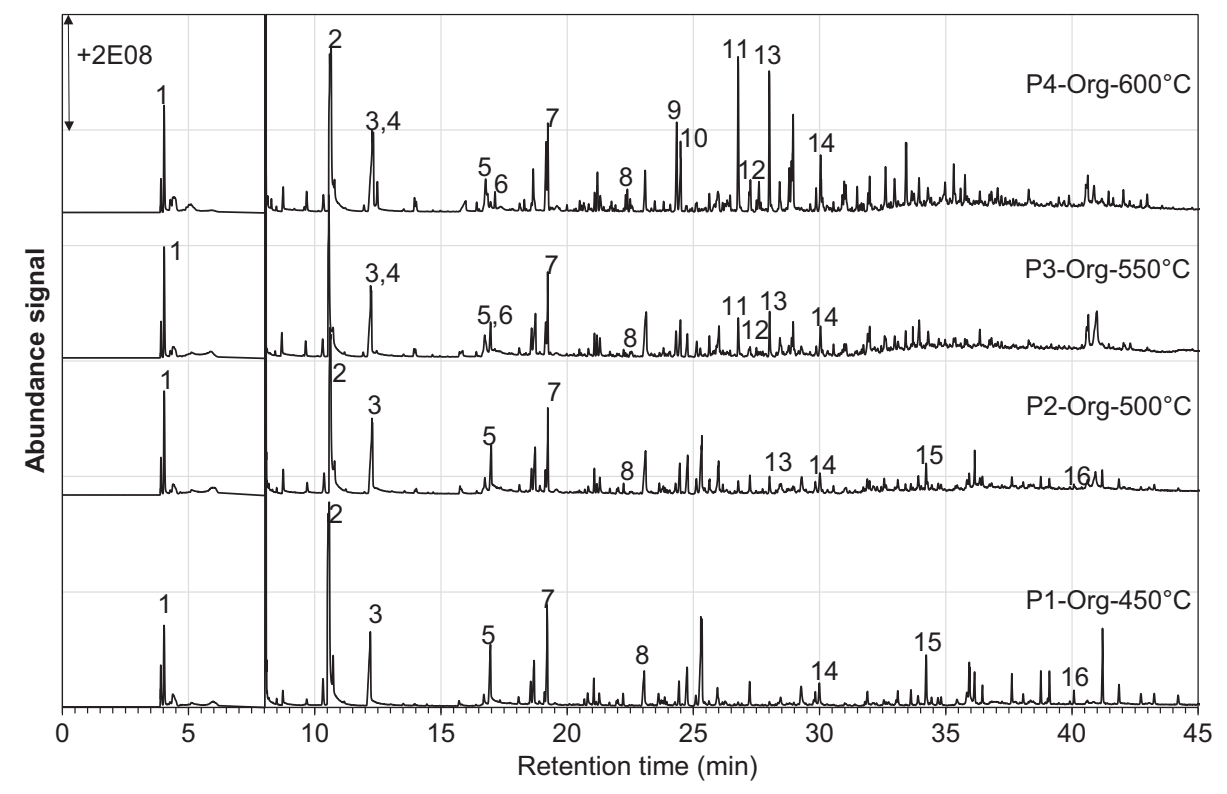

Fig. 6. GC/MS analysis of pyrolysis bio-oils.

Table 8

Standards for several commercial fuels and typical values found for hydrothermal and pyrolysis oils.

\begin{tabular}{|c|c|c|c|c|c|}
\hline & Diesel & Biodiesel & Marine heavy fuel oil & Hydrothermal oil & Pyrolysis oi \\
\hline Standard & NF EN 228 & NF EN 14214 & NF ISO 8217 & & In progress \\
\hline Density at $15^{\circ} \mathrm{C}\left(\mathrm{kg} \mathrm{m}^{-3}\right)$ & $820-845$ & $860-900$ & $920-1010$ & 1.14 & 1.1 \\
\hline Carbon residue $(\%)$ & $<0.3$ & $<0.3$ & $<2.5-20$ & $17-24$ & $11-13$ \\
\hline Total acid number (mg KOH per gram of fuel) & $<0.5$ & $<0.5$ & $<0.5$ & $32-67$ & $45-109$ \\
\hline Iodine value ( $\mathrm{g}_{\mathrm{I} 2} / 100 \mathrm{~g}$ of fuel) & NA & $<120$ & NA & $126-127$ & $147-203$ \\
\hline Higher heating value $\left(\mathrm{MJ} \mathrm{kg}^{-1}\right)$ & 45 & $\geqslant 35$ & NA & $27-30$ & $21-25$ \\
\hline Water content (\%) & $<0.02$ & $<0.05$ & $<0.033$ & $<1$ & $8-20$ \\
\hline Viscosity at $40^{\circ} \mathrm{C}$ (mPa s) & $3-4$ & $<4$ & $8.5-690$ & 67,000 & $13-70$ \\
\hline
\end{tabular}

\section{Discussion}

As mentioned in the introduction, commercial fuels are not generic and each responds to a specific need. Norms and standards are designed to make sure that the application operates correctly for any commercial fuel for that particular application. Table 8 presents the requirements for some commercial fuels and typical values for bio-oils found in this study. From the presented results it is clear that both hydrothermal and pyrolysis oils are far from a dropin commercial use.

In the case of hydrothermal oils, industrial applications are still far. The viscosity is very high and this may not be acceptable for most applications. Viscosity for hydrothermal oils produced from blackcurrant pomace as presented by Anouti et al. [40] is much lower. Acidity is also very high, even when the oils are produced under basic conditions. In practice hydrothermal oils will need to be upgraded to respond to commercial applications [41]. The results presented in this paper are valid for beech wood converted in batch reactors. Other reactor technologies may and will yield slightly different products. Projections towards other technologies and resources are risky.

Pyrolysis oils are also far from commercial fuels. The growing interest in pyrolysis oils and the (slow) start of commercial production has sparked off discussions to create standards for pyrolysis oils [15]. In practice due to the acidity and stability specific applications will be developed. Drop in applications seem far away without extensive upgrading.

The oxygen content as found in this study for both pyrolysis oils as hydrothermal oils are comparable to those found in previous studies as presented in Section 2. From the literature it appears that hydrothermal oil produced in batch reactors $[17,18]$ contain more oxygen than oil produced in continuous reactors $[19,20]$. A possible explanation may be found in the longer heating times, leading to some carbonisation before liquefaction takes place. Globally the hydrogen content of hydrothermal oils and pyrolysis oils are quite similar. The differences are in the ratio between oxygen and carbon, this being higher for pyrolysis oils. Hydrothermal oils may be better suited for catalytic hydro-deoxygenation. It is clear however that information on $\mathrm{CHO}$ alone is far from sufficient to evaluate bio-oils.

It is interesting to note that many of the same degradation products from lignin are found in both pyrolysis oils and hydrothermal oils. These products generate high iodine values. The limitation on the iodine value in biodiesel is due to unsaturations in the fatty acids leading to wax forming by polymerisation. It appears that the test is not specific, and sterically hindered double bonds are also indicated by this test.

\section{Conclusions}

This paper clearly shows that bio-oils are far from being commercial drop-in fuels. Both hydrothermal and pyrolysis oils suffer from a very high acidity. This means that storage and transfer facilities need to be adjusted. High iodine values also indicate potential storage problems. Upgrading to reduce the oxygen content (acidity), saturate double bonds (iodine value) and depolymerise high molecular weight compounds (viscosity) will be unavoidable for drop-in applications. 
Bio-oils present an interesting source of liquid fuels that merits the eventual development of specific applications and standards to guarantee a reliable operation of the application. In practice, hydrothermal oils from beech wood, as found in this study, will need to be heated before injection because of their high viscosity. The viscosity of the organic fraction of pyrolysis bio-oils is higher than that of commercial fuels. The presence of water (when mixing the aqueous and organic fractions) lowers significantly the viscosity. Water is however undesirable for combustion applications as it reduces the heating value. In addition, the aqueous and organic fractions are only miscible in certain amounts before phase separation occurs.

The addition of a strong base in the hydrothermal conversion process increases the oil yield, and improves the viscosity of the oil. However this is not sufficient and other catalysts should be considered. Increasing severity in the fast pyrolysis process decreases the acidity of the oil at the expense of an increased iodine values, and leads to an increase of lighter molecules at the expense of higher molecular weight compounds.

\section{Acknowledgments}

The authors would like to acknowledge financial support from the French Research National Agency ANR (LIQHYD project, Grant No ANR-12-BIME-003) and the CCIAG (Boil project). The authors are also grateful to Julien Roussely, Marine Blanchin, Hélène Miller and Sébastien Thiery for help on analysis of the products.

\section{References}

[1] Kruse A, Dahmen N. Water - a magic solvent for biomass conversion. J Supercrit Fluids 2015;96:36-45.

[2] Hammerschmidt A, Boukis N, Hauer E, Galla U, Dinjus E, Hitzmann B, et al. Catalytic conversion of waste biomass by hydrothermal treatment. Fuel 2011;90:555-62.

[3] Itoh S, Suzuki A, Nakamura T, Yokohama S. Production of heavy oil from sewage sludge by direct thermochemical liquefaction. Desalination 1994;98:127-33.

[4] Déniel M, Haarlemmer G, Roubaud A, Weiss-Hortala E, Fages J. Hydrothermal liquefaction of food processing residues: application to blackcurrant pomace. In: 23st European biomass conference and exhibition (EUBCE 2015), Vienna, Austria; 2015.

[5] Déniel M, Haarlemmer G, Roubaud A, Weiss-Hortala E, Fages J. Energy valorisation of food processing residues and model compounds by hydrothermal liquefaction. Renew Sustain Energy Rev 2016;54:1632-52.

[6] Hognon C, Delrue F, Texier J, Grateau M, Thiery S, Miller H, et al. Comparison of pyrolysis and hydrothermal liquefaction of Chlamydomonas reinhardtii. Growth studies on the recovered hydrothermal aqueous phase. Biomass Bioenergy 2015;73:23-31.

[7] Minowa T, Kondo T, Sudirjo ST. Thermochemical liquefaction of Indonesian biomass residues. Biomass Bioenergy 1998;14:517-24.

[8] Zhong C, Wei X. A comparative experimental study on the liquefaction of wood. Energy 2004;29:1731-41.

[9] Pinkowska H, Wolak P. Hydrothermal decomposition of rapeseed straw in subcritical water. Proposal of three-step treatment. Fuel 2013:113:340-6.

[10] Gan J, Yuan W. Operating condition optimization of corncob hydrothermal conversion for bio-oil production. Appl Energy 2012;103:350-7.

[11] Goudriaan F, Peferoen DGR. Liquid fuels from biomass via a hydrothermal process. Chem Eng Sci 1990;45:2729-34.

[12] Bridgwater AV, Peacocke GVC. Fast pyrolysis processes for biomass. Renew Sustain Energy Rev 2000;4:1-73.

[13] Zhu Y, Biddy MJ, Jones SB, Elliott DC, Schmidt AJ. Techno-economic analysis of liquid fuel production from woody biomass via hydrothermal liquefaction (HTL) and upgrading. Appl Energy 2014;129:384-94.
[14] Wiggers VR, Wisniewski Jr A, Madureira LAS, Barros AAC, Meier HF. Biofuels from waste fish oil pyrolysis: continuous production in a pilot plant. Fuel 2009;88:2135-41.

[15] Oasmaa A, van de Beld B, Saari P, Elliott DC, Solantausta Y. Norms, standards and legislation for fast pyrolysis bio-oils from lignocellulosic biomass. Energy Fuels 2015;29:2471-84.

[16] Wang F, Chang Z, Duan P, Yan W, Xu Y, Zhang L, et al. Hydrothermal liquefaction of Litsea cubeba seed to produce bio-oils. Bioresour Technol 2013;149:509-15.

[17] Nazari L, Yuan Z, Souzanchi S, Ray MB, Xu C. Hydrothermal liquefaction of woody biomass in hot-compressed water: catalyst screening and comprehensive characterization of bio-crude oils. Fuel 2015;162:74-83.

[18] Doassans-Carrère N, Ferrasse J-H, Boutin O, Mauviel G, Lédé J. Comparative study of biomass fast pyrolysis and direct liquefaction for bio-oils production: products yield and characterizations. Energy Fuels 2014;28:5103-11.

[19] Elliott DC, Biller P, Ross AB, Schmidt AJ, Jones SB. Hydrothermal liquefaction of biomass: developments from batch to continuous process. Bioresour Technol 2015;178:147-56.

[20] Tews IJ, Solantausta YZY, Drennan CV, Elliott DC, Snowden-Swan LJ, Onarheim K. Biomass direct liquefaction options: technoeconomic and life cycle assessment. Richland (Washington): Pacific Northwest National Laboratory; 2014.

[21] Zhang Q, Chang J, Wang T, Xu Y. Review of biomass pyrolysis oil properties and upgrading research. Energy Convers Manage 2007;48:87-92.

[22] Mohan D, Pittman CU, Steele PH. Pyrolysis of wood/biomass for bio-oil: a critical review. Energy Fuels 2006;20:848-89.

[23] Oasmaa A, Elliott CD, Korhonen J. Acidity of biomass fast pyrolysis bio-oils. Energy Fuels 2010;24:6548-54.

[24] Staš M, Kubička D, Chudoba J, Pospíšil M. Overview of analytical methods used for chemical characterization of pyrolysis bio-oil. Energy Fuels 2014;28:385-402.

[25] Mullen CA, Boateng AA. Chemical composition of bio-oils produced by fast pyrolysis of two energy crops. Energy Fuels 2008;22:2104-9.

[26] Collura S, Azambre B, Weber J-V. Thermal behaviour of Miscanthus grasses, an alternative biological fuel. Environ Chem Lett 2005;3:95-9.

[27] Gautam A, Agarwal AK. Determination of important biodiesel properties based on fuel temperature correlations for application in a locomotive engine. Fuel 2015;142:289-302.

[28] Zhu Z, Rosendahl L, Toor SS, Yu D, Chen G. Hydrothermal liquefaction of barley straw to bio-crude oil: effects of reaction temperature and aqueous phase recirculation. Appl Energy 2015;137:183-92.

[29] Ghetti P. A rapid heating TGA method for evaluating the carbon residue of fuel oil. Fuel 1994;73.

[30] Septien-Stringel S. High temperature gasification of millimetric wood particles between $800{ }^{\circ} \mathrm{C}$ and $1400{ }^{\circ} \mathrm{C}$. Toulouse, France: Institut National Polytechnique de Toulouse, Université de Toulouse; 2011.

[31] Couhert C, Commandré J-M, Salvador S. Failure of the component additivity rule to predict gas yields of biomass in flash pyrolysis at $950{ }^{\circ} \mathrm{C}$. Biomass Bioenergy 2009;33:316-26.

[32] Billaud J, Valin S, Ratel G, Thiery S, Salvador S. Biomass gasification between 800 and $1400{ }^{\circ} \mathrm{C}$ in the presence of $\mathrm{O}_{2}$ : drop tube reactor experiments and simulation. Chem Eng Trans 2014;37:163-8.

[33] Gorton CW, Kovac RJ, Knight JA, Nygaard TI. Modeling pyrolysis oil production in an entrained-flow reactor. Biomass 1990;21:1-10.

[34] García Barneto A, Carmona JA, Barrón A. Thermogravimetric monitoring of crude oil and its cuts in an oil refinery. Energy Fuels 2015;29:2250-60.

[35] Hashimoto N, Nomura H, Suzuki M, Matsumoto T, Nishida H, Ozawa Y Evaporation characteristics of a palm methyl ester droplet at high ambient temperatures. Fuel 2015;143:202-10.

[36] Gonçalves MLA, Ribeiro DA, da Mota DAP, Teixeira AMRF, Teixeira MAG Investigation of petroleum medium fractions and distillation residues from Brazilian crude oils by thermogravimetry. Fuel 2006;85:1151-5.

[37] Hurd CD, Martin KE. Ketene from acetic acid. J Am Chem Soc 1929;51:3614-7.

[38] Szwarc M, Murawski J. The kinetics of the thermal decomposition of acetic anhydride. Trans Faraday Soc 1951;47:269-74.

[39] Hoffmann J, Jensen CU, Rosendahl LA. Co-processing potential of HTL biocrude at petroleum refineries - Part 1: Fractional distillation and characterization. Fuel 2016;165:526-35.

[40] Anouti S, Haarlemmer G, Déniel M, Roubaud A. Analysis of physicochemical properties of bio-oil from hydrothermal liquefaction of blackcurrant pomace. Energy Fuels 2016;30:398-406.

[41] Biller P, Sharma BK, Kunwar B, Ross AB. Hydroprocessing of bio-crude from continuous hydrothermal liquefaction of microalgae. Fuel 2015;159:197-205. 